on the high roads, this can be avoided by availing oneself of the many paths through the olive groves, where one is protected both from wind and dust. The roads are kept in excellent order, and that is one reason why there is comparatively little dust.

There is an ample supply of excellent food. Muuntain mutton, beef, game, fresh-water fish, good bread, abundance of vegetables, and truit are afforded by the locality itself, while sea fish and poultry are brought from Cannes. The water-supply is abundant and good, but the water is rather hard from the presence of chalk.

My own visit to Grasse was necessarily a brief one; but my most trustworthy informant, whom I have already quoted, writing of the hotel accommodation, says: "Here one has every comfort. The sanitary arrangements are most carefully studied and carried out on English principles. Most of the bedrooms and sittingrooms have a southern aspect. The charges are from 10 francs to 16 francs a day for pension. The food and cooking are very good indeed. The house is well warmed throughout. The chief amusement is walking or driving through lovely scenery in the bracing mountain air. There is lawn tennis in the hotel grounds, also an excellent fencing room. Trout fishing is to be had in the Loup and also in the Siagne. The roads are all of easy gradient, and the Route Nationale, which passes in front of the hotel, is almost absolutely level, thus enabling invalids to take walking exercise with perfect comfort."

Of the various excursions which the attractive country around affords, this gentleman observes: "The favourite expeditions are the Gorge and Saut de Loup, where there is some very bold scenery ; Gourdon, an old fortified place commanding the entrance to the Gorge de Loup, to which there is a good carriage road; Pégomas and Auribeau on the Siagne, both within an easy drive; Casteleras, from which there is a most lovely panorama containing twenty villages, showing for its boundaries the snow-covered Alpes-Maritimes, the Basses-Alpes, the Mediterranean, and the Esterels; Mongins, with its old fortifications; St. Vallier, on the Digne road, on the journey to which are some lovely views; Cabris, an old place most picturesquely situated to the south-west of St. Vallier; St. Césaire, peruhed on the edge of a precipitous cliff overhanging the Siagne; near home we have the Plateau Napoleon, on the top of the Rocavignon Spur, where the great Emperor, having been refused admission into Grasse, breakfasted on his journey to Paris after his escape from Elba."

Grasse itself is an industrial town of considerable wealth, carrying on a flourishing trade in the manufacture of scents, liqueurs, soaps, candied fruits, wine, olive oil, etc. The cultivation of flowers for the manufacture of scent gives occupation to a number of families, and the extensive gardens that surround the town consist almost entirely of orange groves and beds of roses and jasmine, while the ground is literally carpeted with violets, jonquils, mignonette, and other odorous plants.

There are some well-kept public gardens and a few objects of antiquarian interest in the town, but nothing of any special importance. It has been stated in some works on the Riviera that hay-fever prevails in Grasse, on account of the diffusion into the air of the pollen and scent of the flowers grown in such abundance for the perfume manufacture; but I am assured, on the faith of an English gentleman who has lived in Grasse for six years that he has only heard of one case amongst visitors during the whole of that period, and that was the case of a gentleman who suffered annually from severe attacks in England. $\mathrm{My}$ informant also states, as the result of his inquiries amongst the medical and other residents there, that this disease is of rare occurrence in the neighbourhood.

The climate of Grasse would seem to be especially useful to those pulmonary or nervous invalids who find themselves better in a tonic, dry, bracing air than in a moist, relaxing one, but who, at the same time, are unable to support the more rigorous climate of such winter resorts as Davos, the Engadine, Grindelwald, or Les Avants. At Grasse they have the advantage of the same warm and brilliant sunshine as they obtain at Cannes or Mentone, but with the benefit, on account of its elevation, of a lighter, somewhat cooler, more tonic air than in these coast towns.

Some cases of asthma appear to prosper remarkably at Grasse, and some sufferers from this malady have built themselves villas there on account of the immunity from attacks they enjoy in that locality.

Many patients also suffer from sleeplessness, loss of appetite, and ne:vous irritability when living on the coast, and many cannot bear the glare of the sun on the sea. To all these, who yet desire to live in the winter under a Provençal sun, and who derive benefit thereby, a trial of Grasse may be recommended.

Also, in the spring months, when the heat becomes a little oppressive on the coast resorts, a migration to the cooler climate of Grasse may prove a beneficial change. There can be no doubt that Grasse has distinct and special climatic advantages, and that they have not hitherto been utilised as much as they deserve to be.

\section{ON RAISING THE EPIGLOTTIS.} BY R O B E R T L. B O W L ES, M.D., F.R.C.P.,

ON October 22nd, 1888, Dr. B. Howard read before the Medical Society of London a paper on "A New and Only Way of Raising the Epiglottis." The first intimation I had of this paper was its publication in the medical journals, and I missed the debate from being told that it would not come on for a year at least, in consequence of Dr. Howard's absence from England. Dr. Howard has done me the honour of quoting me in his paper, but not, I think, in a way for my views to be well understood. I would, therefore, wish to give publicity to the following extracts from some papers of my own, by which it will be seen that I had already done (at various times since 1856) all the work which is now in 1888 presented to the public as new and original.

Extract No. 1, is a letter to the Lancet from R. L. Bowles, 1856, and reproduced in Dr. Marshall Hall's book on Drowning in August, 1857: "On cutting down and removing the right side of the pharynx, with the corresponding halves of the hyoid bone and thyroid cartilage, in another subject, a tolerable view of the position of the parts was obtained. The epiglottis was in direct apposition, by its laryngeal surface, with the posterior wall of the pharynx, so as to preclude the possibility of the passage of air. When, however, the head was allowed to hang backwards over the edge of the table, the bending of the cervical vertebræ causea the posterior wall of the pharynx to recede from the epiglottis, so as to allow the free passage of air. If the tongue had been drawn forwards, would the epiglottis have been removed from the pharynx, or would the prone position cause it to tall forwards?"

Extract No. 2, from "Observations on Stertor," by Robert L. Bowles, in the Medico-Chirurgical Transactions, 1860 : “It is well known that the cavity of the pharynx, having a fixed boundary only posteriorly, may have its capacity materially affected by the ever-varying position of its sides, of the soft palate, the tongue, and the larynx. The larynx and the sides of the pharynx have, I believe, little connection with the cause of stertor. I shall, therefore, not further refer to them. The tongue, being attached to the lower jaw by its mucous membrane and its muscles, has its relations with surrounding parts altered as the mouth is opened or closed.

"When the mouth is closed the ramus of the jaw forms nearly a right angle with the spinal column, from which the symphysis is then at its greatest distance. When the mouth is opened by the dropping of the jaw, the symphysis describes the arc of ' a circle, and approaches more nearly to the spine, where the posterior wall of the pharynx is attached. (See drawing at end of paper, Fig. 1.) The tongue, having its chief attachment to the symphysis, would consequently be drawn from the pharynx in the former case, and allowed to rest in contact with it in the latter. This, if not true in every case, is at least true in some, as the plate demonstrates. (See Fig. 2.)

"The dissection from which the drawing was taken was made with great care, so as not to displace the parts more than was necessary to give a fair view of the base of the tongue and the epiglottis. The two sketches, with the open and closed mouth, we:e kindly taken for me on the spot by my friend Mr. (now Dr.) Fitzgerald, and they very accurately represent the parts as they appeared at the time. When the mouth was opened and the subject on its back, the road to the larynx was completely obstructed in consequence of the tongue resting in contact with the back of the pharynx; but the obstruction could be removed by hooking the tongue forward. When the mouth was closed the tongue was lifted from the pharynx, leaving ample breathing space. But, even with the closed mouth, if the chin were much bent on the sternum, the base of the tongue was almost in contact with the back of the pharynx.

"It would seem from this dissection that the muscles of the tongue attaching it to the symphysis of the jaw, are too short to admit of the base of the tongue reaching the back of the throat 
when the mouth is closed. The purpose served by such an arrangement would appear to be to keep the base of the tongue away from the back of the throat during deglutition. In the act of deglutition the mouth is firmly closed, and the genio-hyoid and genio-hyo-glossi muscles taking their fixed point from the now immovable symphysis, draw the body of the tongue upwards and forwards, allowing sufficient room for the morsel of food to travel easily through the cavity of the pharynx. Were these muscles of greater length the base of the tongue might become a source of inconvenience, if not of danger. The dissection, besides demonstrating the respective positions of the tongue with the open and closed mouth, suggests the necessity of caution being used in raising the head with pillows; for if the head be too much bent forward on the chest the tongue may lie in dangerous proximity to the pharynx, even if the mouth bo closed."

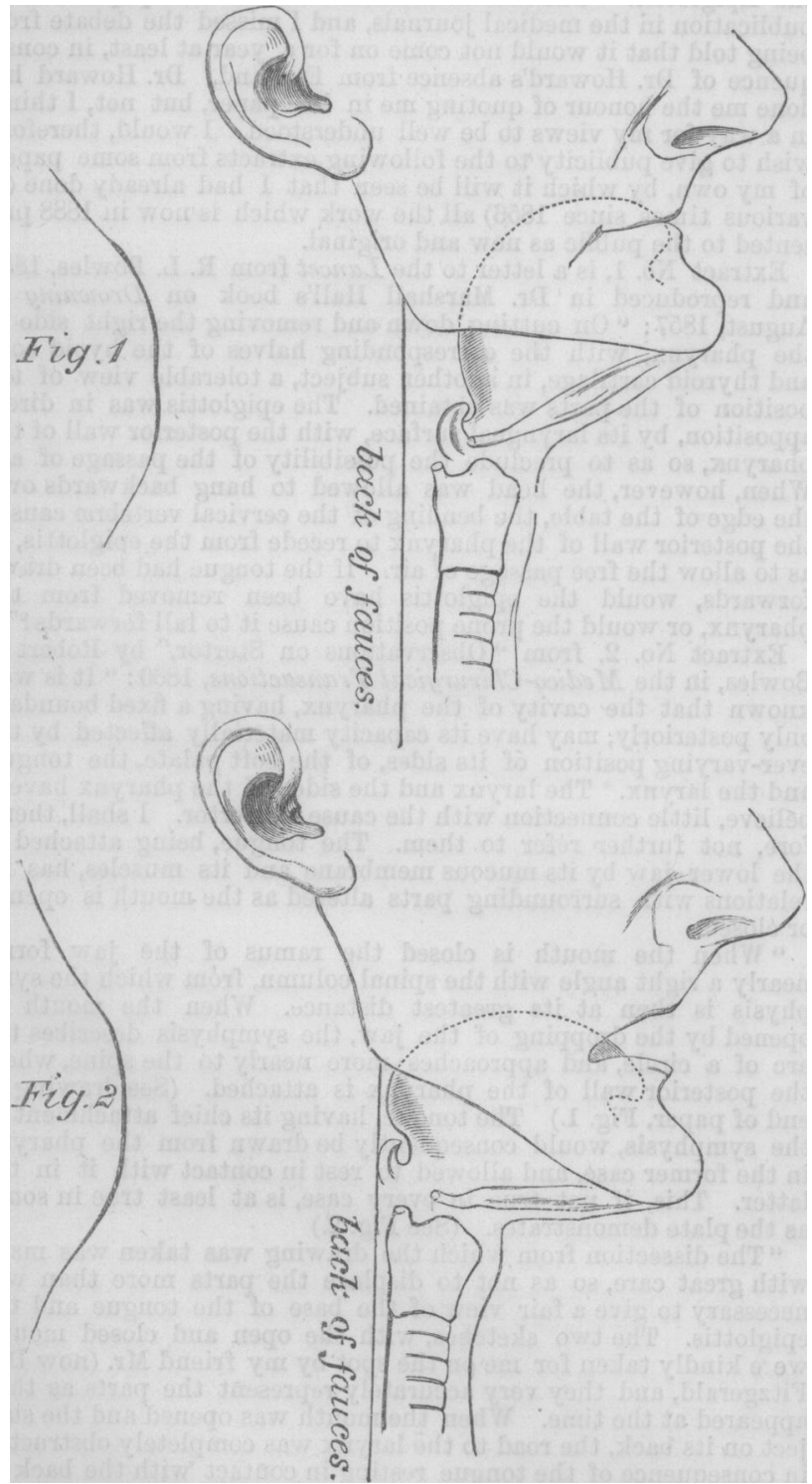

Ex/ract No. 3, from a paper read by Robert L. Bowles at Canterbury, November 28th, 1863, and published in the JourNal of February 6th, 1864: "When the patient is in the position recommended in the Silvester method, the tongue may appear to an unpractised eye to be well forward, while the base of it lolls back and covers the glottis; and if there be fluids in the stomach (which is not uncommon), they are very liable to be thrown up into the pharynx when pressure is made on the sternum; and when the pressure is removed, the next inspiration would cer- tainly draw the fluid into the bronchial tubes.......... Only a fortnight ago, I was present at the reduction of a dislocation of the shoulder in a county infirmary. The patient was sitting on a chair fastened to a post, whilst the pulleys were on the arm. After chloroform had been administered for some time, the man suddenly ceased breathing and became deadly pale, the jaw dropped, and the tongue touched the incisor teeth. The gentleman who had charge of the chloroform immediately procured water and dashed it on the face and back. Seeing the man did not recover, I at once, though a stranger, introduced my finger into his mouth and hooked up the base of the tongue, when the patient instantly inspired, and rallied without further difficulty."

Extract No. 4, from a case mentioned in "Further Observations on Stertor, its Pathology and Treatment," by Robert L. Bowles, read before the Royal Medical and Chirurgical Society, May, 1870, and published in the Lancet of 1881 : "Presently he began snoring whilst he was on his side; his chin was bent upon the sternum; on straightening the neck he was quiet."

Extract No. 5, from notes of conversation between Dr. Bowles and the chief clerk of the Royal National Lifeboat Institution, made by the latter, and sent to Dr. Bowles on the following day by the secretary, Mr. Richard Lewis (May 21st, 1880). Dr. Bowles states: "that the mere drawing forward of the tongue and securing it by an elastic band does not have the supposed effect of drawing with it the epiglottis and leaving the glottis open."

From these extracts it will, I think, be seen that Dr. Howard claims too much in asserting that his method is the new and only way of raising the epiglottis, or that it is, as he expressed it in his paper, "my discovery." I should rather have said that everything he has done was undertaken to test the truth of what I had told him, for at his request, in 1881, I sent him my paper on Stertor, and three or four years later he called upon me, and at our interview we fully and freely discussed the whole question of the relation of the tongue and the epiglottis to the posterior wall of the pharynx.

Soon after 1860 I undertook some experiments on myself, on the dead subject, and on animals, to test the utility of drawing the tip of the tongue forward, and I found that it was quite useless as a dependable proceeding; the experiment answered, in fact, the question raised at my first dissection (extract No. 1) for the display of the relations of the throat in the supine position. It was, moreover, made clear that in cases of coma, drowning, sedative poisonings, and allied conditions, in all cases, in short, in which physical have supplanted vital forces, that impediments to respiration may always be removed from the back of the throat by simply placing the patient on his side, slightly prone, and keeping the chin well away from the sternum, so that it became unnecessary to trouble in individual cases whether it was the base of the tongue or the epiglottis, or both, which blocked the way. At medical meetings in London, and wherever and whenever the Silvester method has been advocated, I have never lost the opportunity of showing how impossible it was to remove the base of the tongue or the epiglottis from the posterior wall of the pharynx by dragging at the tongue's tip, or by fixing it by an india-rubber band, or by any such device. The truth is that the work done by us (Dr. E. Long Fox, the late Charles Hunter, and myself) for the late Dr. Marshall Hall, in 1856, was fundamental, and must be fully taken into account in all investigations undertaken to elucidate the principles or the practice of relieving the difficulties of respiration connected with the throat and the upper air-passages.

BEQUESTS AND DoNations. - It is announced that the trustees of the William Dudley Trust are again this year enabled to make the following Christmas donations:-The Birmingham and Midland Royal Orthopædic Hospital, £200. The Birmingham Medical Mission, £200. The Slaney Street Ragged School, £50. The Samaritan Fund in connection with the General Hospital, $£ 50$. We understand that these grants are made by the trustees in exercise of the discretionary power which is vested in them by the late Mr. William Dudley, the benevolent founder of the trust, whereby the trustees are enabled to apply any available surplus income of this charity in aid of the Birmingham charities which have for their object the relief of human suffering.-The late Mr. E. A. D. Brooshooft, of Kirk Ella, East Riding, has left a legacy of $£ 5,000$ to the Sheffield Infirmary, and $£ 1,000$ to the Public Hospital. 